\title{
EVALUATION OF HYPOLIPIDEMIC ACTIVITY OF FRUIT RIND EXTRACTS OF GARCINIA GUMMI- GUTTA IN DIET-INDUCED HYPERLIPIDEMIC RATS
}

\author{
BARATHANE DATCHANAMURTY ${ }^{1 *}$, MANIMEKALAI K², KARTIK J SALWE² \\ ${ }^{1}$ Department of Pharmacology, Vinayaka Missions Medical College, Vinayaka Missions Research Foundation (Deemed to be University), \\ Karaikal, Pondicherry, India. ${ }^{2}$ Department of Pharmacology, Mahatma Gandhi Medical College and Research Institute, Sri Balaji \\ Vidyapeeth University, Pondicherry, India. Email: barathane20@gmail.com
}

Received: 30 June 2018, Revised and Accepted: 30 November 2018

ABSTRACT

Objective: The objective of the study was to evaluate the hypolipidemic activity of fruit rind extracts of Garcinia gummi-gutta in diet-induced hyperlipidemic rats.

Methods: Hydroalcoholic extract of fruit rinds of G. gummi-gutta was prepared using Soxhlet apparatus. 30 Wistar albino rats were divided into five groups $(n=6)$. Except for Group 1, all the other groups were treated with hyperlipidemic diet (HLD) for 4 weeks. After induction, the Groups 3 and 4 were treated with the extracts at $100 \mathrm{mg} / \mathrm{kg}$ and $200 \mathrm{mg} / \mathrm{kg}$ doses, respectively, whereas Group 5 received the standard drug atorvastatin at $10 \mathrm{mg} / \mathrm{kg}$ for the next 4 weeks. Lipid profile was estimated at the end of each week. At the end of the study, rats were sacrificed and the liver and heart were analyzed for histopathological changes. Data expressed as mean \pm standard error of the mean. Statistical analysis was done using one-way ANOVA followed by post hoc Tukey test. $\mathrm{p}<0.05$ considered statistically significant.

Results: The serum levels of total cholesterol (TC), triglycerides (TG), very low-density lipoprotein (VLDL), and LDL were significantly increased and the levels of high-density lipoprotein (HDL) were significantly decreased when compared to normal control. The groups which received G. gummi-gutta rind extract at $100 \mathrm{mg} / \mathrm{kg}$ and $200 \mathrm{mg} / \mathrm{kg}$ showed a significant decrease in the mean cholesterol, TG, LDL, VLDL levels, and an increase in HDL levels when compared to the HLD group. The group which received the extract at higher dose (REGG200) was found better than the lower dose (REGG 100). REGG 200 showed significant improvement in increasing the HDL levels than all the test groups. The standard drug atorvastatin was found better than REGG100 but there was no significant difference between high doses of the extract and atorvastatin.

Conclusion: The fruit rinds extract of G. gummi-gutta was able to decrease the elevated serum lipids (TC, TG, LDL, and VLDL) and consequently increase the HDL levels in a dose-dependent manner.

Keywords: Garcinia gummi-gutta, Hypolipidemic, Atorvastatin, Lipid profile.

(C) 2019 The Authors. Published by Innovare Academic Sciences Pvt Ltd. This is an open access article under the CC BY license (http://creativecommons. org/licenses/by/4. 0/) DOI: http://dx.doi.org/10.22159/ajpcr.2019.v12i3.28201

\section{INTRODUCTION}

Cardiovascular disease (CVD) was previously assumed to be a problem of developed and industrialized nations, but over the past few decades, it has slowly infiltrated into the low and middle-income countries where it accounts for nearly $30 \%$ of all deaths [1]. In India, the prevalence of CVD has grown exponentially and accounts for nearly $24 \%$ of all adult deaths [2]. Reports submitted by the National Commission on Macroeconomics and Health have estimated that there would be 62 million patients with coronary artery disease by 2015 and of these 23 million would be people younger than 40 years [3]

The umbrella term CVD has multifactorial etiopathogenesis and its prevalence is attributed to lifestyle changes due to urbanization, stress, lack of physical activity, nutritional transitions, and other metabolic disorders such as diabetes and hypothyroidism.

For decades, dyslipidemia has been identified as an independent modifiable risk closely associated with the incidence of CVD. Furthermore, increased levels of low-density lipoprotein (LDL) with a concurrent decrease in high-density lipoprotein (HDL) contribute to the process of atherogenesis and evolution of atheromatous plaque [4].

Conventional preparations of lipid-lowering drugs such as statins, fibrates, bile acid sequestrants, and niacin are efficient in lowering serum lipids but not always free of side effects [5].
For many years plants and plant products have been identified as a potentially safer alternative to synthetic drugs. Despite such intensive research on various herbal medicines, many species of plants are still left unexplored.

Garcinia gummi-gutta also known as Garcinia cambogia is a diminutive purple fruit native to India and Southeast Asia. The fruit rinds find its use as a food preservative, flavoring agent, and carminative [6]. Traditionally, it is used for the treatment of constipation, piles, rheumatism, edema, menstrual abnormalities, and parasitic infestations [7]. Although many of its biological effects have been explored to depth, still satisfactory studies to exploit its hypolipidemic activity have not been conducted. Therefore, the present study was planned to evaluate the hypolipidemic activity of G. gummi-gutta fruit extract using animal models.

\section{METHODS}

Collection and identification of plant materials

The fruit of G. gummi-gutta was collected during the winter season in the month of August from Palode area of Thiruvananthapuram district, Kerala, India, and was authenticated by a local botanist from Science College. The fruit rinds weighing $5 \mathrm{~kg}$ were separated along the grooves and deseeded. They were later cleaned, shade dried, pulverized, and stored in airtight containers until the commencement of the extraction process. 


\section{Preparation of rind extract}

Hydroalcoholic extract was prepared as per the procedure elaborated by Mahanta and Mukherjee [8]. About 40-45 g of dried powder was packed in the thimble of Soxhlet apparatus, and extraction was carried out continuously with $95 \%$ ethanol refluxing at $50-70^{\circ} \mathrm{C}$ which yielded a dark brown sticky mass. The extract was concentrated and dried using a ventilated oven at $45^{\circ} \mathrm{C}$ for $24 \mathrm{~h}$. The stock powder was stored in a glass desiccator at $4{ }^{\circ} \mathrm{C}$. The total yield per cycle was around $15 \%$ $(\sim 6 \mathrm{~g})$ per cycle.

\section{Chemicals}

Pure cholesterol and cholic acid were obtained from Loba Chemie Pvt., Ltd., Mumbai. Atorvastatin (Lipvas) of Cipla Company, Mumbai, was procured from a local medical store. 2-thiobarbituric acid was purchased from Sigma Aldrich, Bengaluru. All other solvents and chemicals used in the study were of analytical grade and purchased from SD fine - chem. Mumbai.

\section{Ethical clearance}

Ethical clearance was taken from Institutional Animal Ethics Committee of the institute before the commencement of the study.

\section{Animals}

Adult male Wistar albino rats 10-12 weeks of age weighing 180 $\pm 20 \mathrm{~g}$ were procured from King's Institute, Guindy, Chennai. They were housed and maintained in the central animal house of the institute 2 weeks before the commencement of the study so that they could adapt to the new environment. Animals were kept in polypropylene cages with dry paddy husk bedding maintaining a room temperature of $26 \pm 2^{\circ} \mathrm{C}$ and relative humidity of $45-55 \%$ with $12: 12 \mathrm{~h}$ dark and light cycle. They were fed with standard pellet diet and water ad libitum. The nutritional value of the standard pellet diet was $21 \%$ of protein, $5 \%$ of lipids, $4 \%$ of crude fiber, $8 \%$ of ash, $1 \%$ of calcium, $0.6 \%$ of phosphorus, $3.4 \%$ of glucose, $2 \%$ of vitamins, $55 \%$ of carbohydrates, and produced energy of $3600 \mathrm{kcal} / \mathrm{kg}$. Care of the animals in the central animal house was strictly in accordance with the guidelines drafted by the Committee for the purpose of Control and Supervision of Experiments on Animals, New Delhi, India.

\section{Acute toxicity testing}

A pilot study was performed using two doses $1000 \mathrm{mg} / \mathrm{kg}$ body weight and $2000 \mathrm{mg} / \mathrm{kg}$ body weight of the fruit rind extract of G. gummi-gutta. The doses selected were 10 and 20 times more than the earlier study. The animals were observed continuously for $4 \mathrm{~h}$ and then occasionally for further $4 \mathrm{~h}$ and finally overnight. Animals were observed for tremors, clonic convulsions, tonic extensions, catatonia, spasticity, opisthotonus, ataxia, sedation, ptosis, and respiration. The animals were continuously observed for 24 and $72 \mathrm{~h}$ for any lethality or death.

\section{Dose selection}

As the limit dose did not exhibit any signs of toxicity, a dose of 200 and $100 \mathrm{mg} / \mathrm{kg}$, p.o., which was $1 / 10^{\text {th }}$ and $1 / 20^{\text {th }}$ of $2000 \mathrm{mg} / \mathrm{kg}$, was taken up for the main study. Atorvastatin at a dose of $10 \mathrm{mg} / \mathrm{kg}$ was taken as standard control.

\section{Hyperlipidemic diet (HLD)}

Method of Blank with modification was used to produce diet-induced hyperlipidemia. HLD was prepared daily by mixing standard pellet diet (92\%), cholesterol (2\%), cholic acid (1\%), and coconut oil (5\%) and was molded into pellets [9].

\section{Experimental design}

A total of 30 healthy adult Wistar albino rats were used in the study. The total duration of the study was 8 weeks. Following acclimatization for 1 week, a baseline measurement of lipid profile was performed for all the rats. In an attempt to eliminate bias, the rats were numbered and grouped based on random numbers generated using computer software.

\section{Induction of hyperlipidemia}

The study consists of five groups with six rats in each group $(n=6)$. Except for Group 1 which received standard pellet diet and water ad libitum, all the remaining four groups received HLD for a period of 30 days.

On day 30, the lipid profile of the rats in all the four groups was estimated and induction of hyperlipidemia was confirmed.

Following successful induction, the rats belonging to those four groups were treated with the extracts, and the standard drug between 9 and 10 am daily for another 30 days suspended in $1 \%$ carboxymethylcellulose and administered using a steel gavage needle (Table 1).

\section{Estimation of lipid profile}

Blood samples for the estimation of lipid profile were taken from the lateral tail vein as per method elaborated by Diehl et al. [10]. Blood samples were collected on day 0 (baseline) and thereafter on $30^{\text {th }}, 45^{\text {th }}$, and $60^{\text {th }}$ day. Serum was separated by centrifugation at $3000 \mathrm{rpm}$ for $10 \mathrm{~min}$. It was then kept frozen at $-20^{\circ} \mathrm{C}$ until analysis. Total cholesterol (TC) level was calculated by the enzymatic method and expressed in $\mathrm{mg} / \mathrm{dl}$. HDL levels were calculated using polyanion precipitation and expressed as $\mathrm{mg} / \mathrm{dl}$. LDL cholesterol level was calculated using Friedewald's equation and expressed in mg/dl. Triglycerides (TG) in serum were converted to glycerol and then estimated using glycerol kinase enzyme based kinetic method and expressed in mg/dl. Very LDL is calculated using the formula:

$$
V L D L=\frac{T G}{5}
$$

At the end of 8 weeks, all the rats were sacrificed by an overdose of sodium pentobarbital $150 \mathrm{mg} / \mathrm{kg}$ i.p. Heart and liver were dissected and washed with the physiological salt solution and fixed with $10 \%$ formalin.

\section{Thiobarbituric acid reactive substances (TBARS) assay}

About $1 \mathrm{ml}$ of serum was mixed with $500 \mu \mathrm{l}$ of $15 \%$ trichloroacetic acid in $0.25 \mathrm{~N}$ hydrochloric acid ( $\mathrm{HCl})$ and $500 \mu \mathrm{l}$ of $0.375 \%$ thiobarbituric acid in $0.25 \mathrm{~N} \mathrm{HCl}$. This was shaken well to mix thoroughly and was then heated in a boiling water bath at $95^{\circ} \mathrm{C}$ for $15 \mathrm{~min}$. After bringing it down to room temperature, it was centrifuged at 1000 r.p.m for $10 \mathrm{~min}$ and the reddish-pink supernatant was collected. Absorbance was determined using Labman double beam UV-visible spectrophotometer (LMSP-UV1900) tuned to a wavelength $(\lambda)$ at $535 \mathrm{~nm}$ against a blank that contained all the reagents minus the serum [11]. The concentration of malondialdehyde (MDA) in the serum was calculated using molar extinction coefficient $1.56 \mathrm{M} / \mathrm{cm}$, and the results were expressed in $\eta \mathrm{mol} / \mathrm{ml}$ of plasma [12].

\section{Histopathology}

The liver and heart fixed in 10\% formalin were washed, dehydrated in descending grades of isopropanol and finally rinsed with xylene. The tissues were then embedded in molten paraffin wax. Sections were cut using a microtome at a thickness of $5 \mu \mathrm{m}$ and then stained with

Table 1: Experimental design

\begin{tabular}{lll}
\hline Group & Purpose & Treatment \\
\hline Group 1 & Normal control & Standard pellet diet+1\% CMC \\
Group 2 & HLD control & HLD+1\% CMC \\
Group 3 & REGG 100 & $\begin{array}{l}\text { HLD+rind extract of G. gummi-gutta } \\
\text { at 100 mg/kg } \\
\text { HLD+rind extract of G. gummi-gutta } \\
\text { at 200 mg/kg }\end{array}$ \\
Group 4 & REGG 200 & HLD+Atorvastatin at 10 mg $/ \mathrm{kg}$ \\
\hline
\end{tabular}

HLD: Hyperlipidemic diet, REGG100: Rind extract of Garcinia gummi-gutta at $100 \mathrm{mg} / \mathrm{kg}$, REGG200: Rind extract of Garcinia gummi-gutta at $200 \mathrm{mg} / \mathrm{kg}$, G. gummi-gutta: Garcinia gummi-gutta, CMC: Carboxymethylcellulose 
hematoxylin and eosin [13]. The sections were observed under light microscope at a magnification of $\times 10$ (Adeltavision Trinocular Digital Microscope) for histopathological changes.

\section{Statistical analysis}

Collected data were entered in Microsoft Excel 2013 and analyzed using SPSS statistical software version 17. Results were expressed in mean \pm standard error of the mean as tables. Statistical analysis was performed using one way ANOVA followed by post hoc Tukey's test. The $\mathrm{p}<0.05$ was considered statistically significant at $95 \%$ confidence interval.

\section{RESULTS}

\section{Acute toxicity study of REGG in rats}

Acute toxicity studies confirmed that the fruit rind extract of G. gummigutta up to a dose of $2000 \mathrm{mg} / \mathrm{kg}$ body weight was non-toxic. No death was observed for up to $72 \mathrm{~h}$. There was no lethality or any toxic reactions found at any of the doses selected until the end of the study.

Effect of the rind extract of G. gummi-gutta on serum lipid levels The serum levels of TC, TG, VLDL, and LDL were significantly increased, and the levels of HDL were significantly decreased when compared to normal control.
The groups which received G. gummi-gutta rind extract at $100 \mathrm{mg} / \mathrm{kg}$ and $200 \mathrm{mg} / \mathrm{kg}$ showed a significant decrease in the mean cholesterol, TG, LDL, VLDL levels, and an increase in HDL levels when compared to the HLD group. The group which received the extract at higher dose (REGG200) was found better than the lower dose (REGG 100). REGG 200 showed significant improvement in increasing the HDL levels than all the test groups.

The standard drug atorvastatin was found better than REGG100, but there was no significant difference between a high dose of G. gummigutta rind extract and atorvastatin. REGG $200 \mathrm{mg} / \mathrm{kg}$ showed a marginal increase in HDL levels than the standard drug (Tables 2-6).

Effect of the rind extract of G. gummi-gutta on TBARS levels

Serum TBARS levels were significantly higher $(3.42 \pm 0.04 \eta \mathrm{mol} / \mathrm{ml})$ in rats treated with HLD. Hyperlipidemia significantly increased lipid peroxidation with the generation of reactive oxygen species due to decreased innate antioxidant activity. The groups treated with the standard drug atorvastatin and the groups treated with REGG at both doses showed a significant decrease in TBARS levels $(\mathrm{p}<0.001)$ when compared to HLD control. The concentration of MDA in REGG $200(1.03 \pm 0.01 \eta \mathrm{mol} / \mathrm{ml})$ was significantly lower when compared with other groups (Fig. 1).

Table 2: Effect of fruit rind extract of Garcinia gummi-gutta on total cholesterol levels

\begin{tabular}{|c|c|c|c|c|}
\hline \multirow[t]{3}{*}{ Groups $(n=6)$} & \multicolumn{4}{|c|}{ Total cholesterol levels (mg/dl) } \\
\hline & \multicolumn{2}{|c|}{ Induction of hyperlipidemia } & \multicolumn{2}{|c|}{ Drug administration } \\
\hline & Day 0 baseline & Day 30 & Day 45 & Day 60 \\
\hline Group 1: Normal control & $62.67 \pm 1.50$ & $61.67 \pm 1.73$ & $64.50 \pm 1.38$ & $65.50 \pm 0.81$ \\
\hline Group 2: HLD control & $64.00 \pm 0.97$ & $128.83 \pm 1.08$ & $135.67 \pm 0.84^{\# \#}$ & $141.33 \pm 1.23$ \\
\hline Group 3: REGG 100 & $65.33 \pm 0.71$ & $131.83 \pm 1.17$ & $127.50 \pm 0.76^{* *, \# \#}$ & $109.17 \pm 1.30^{* *, \# \#}$ \\
\hline Group 4: REGG 200 & $64.17 \pm 1.17$ & $129.33 \pm 0.49$ & $113.17 \pm 0.91^{* *, \# \#}$ & $99.33 \pm 1.26^{* * \# \# \#}$ \\
\hline Group 5: Standard control & $65.83 \pm 1.66$ & $129.00 \pm 1.18$ & $106.00 \pm 0.97 * *$ & $93.67 \pm 0.80^{* *}$ \\
\hline
\end{tabular}

Data expressed as mean $\pm S E M . \mathrm{n}=6$ in each group. Significance at ${ }^{*} \mathrm{p}<0.05,{ }^{* *} \mathrm{p}<0.001$ as compared to HLD control, ${ }^{*} \mathrm{p}<0.05,{ }^{* \#} \mathrm{p}<0.001$ as compared to standard control. HLD: Hyperlipidemic diet, REGG 100 and REGG 200: Rind extract of Garcinia gummi-gutta at $100 \mathrm{mg} / \mathrm{kg}$ and $200 \mathrm{mg} / \mathrm{kg}$, Standard control: Atorvastatin $10 \mathrm{mg} / \mathrm{kg}$, SEM: Standard error of mean

Table 3: Effect of fruit rind extract of Garcinia gummi-gutta on triglyceride levels

\begin{tabular}{|c|c|c|c|c|}
\hline \multirow[t]{3}{*}{ Groups $(n=6)$} & \multicolumn{4}{|c|}{ Triglyceride levels (mg/dl) } \\
\hline & \multicolumn{2}{|c|}{ Induction of hyperlipidemia } & \multicolumn{2}{|c|}{ Drug administration } \\
\hline & Day 0 baseline & Day 30 & Day 45 & Day 60 \\
\hline Group 1: Normal control & $79.83 \pm 1.25$ & $79.67 \pm 1.28$ & $80.50 \pm 0.96$ & $82.33 \pm 1.09$ \\
\hline Group 2: HLD control & $83.83 \pm 0.87$ & $182.50 \pm 1.18$ & $197.83 \pm 2.95^{\# \#}$ & $204.00 \pm 3.22$ \\
\hline Group 3: REGG 100 & $81.67 \pm 0.88$ & $181.50 \pm 1.12$ & $165.17 \pm 1.47^{* *, \# \#}$ & $148.50 \pm 1.77^{* *, \# \#}$ \\
\hline Group 4: REGG 200 & $81.17 \pm 1.08$ & $179.83 \pm 1.30$ & $143.33 \pm 1.45^{* *, \# \#}$ & $115.33 \pm 1.26^{* *, \# \#}$ \\
\hline Group 5: Standard control & $83.50 \pm 0.76$ & $180.50 \pm 0.76$ & $120.17 \pm 1.30^{* *, \# \#}$ & $106.17 \pm 1.28^{* *}$ \\
\hline
\end{tabular}

Data expressed as mean \pm SEM. $n=6$ in each group. Significance at ${ }^{*} \mathrm{p}<0.05,{ }^{* *} \mathrm{p}<0.001$ as compared to HLD control. ${ }^{*} \mathrm{p}<0.05$, ${ }^{\#} \mathrm{p}<0.001$ as compared to standard control. HLD: Hyperlipidemic diet, REGG 100 and REGG 200: Rind extract of Garcinia gummi-gutta at 100 mg/kg and 200 mg/kg, Standard control: Atorvastatin 10 mg/kg, SEM: Standard error of mean

Table 4: Effect of fruit rind extract of Garcinia gummi-gutta on low-density lipoprotein cholesterol levels

\begin{tabular}{|c|c|c|c|c|}
\hline \multirow[t]{3}{*}{ Groups $(n=6)$} & \multicolumn{4}{|c|}{ LDL levels (mg/dl) } \\
\hline & \multicolumn{2}{|c|}{ Induction of hyperlipidemia } & \multicolumn{2}{|c|}{ Drug administration } \\
\hline & Day 0 baseline & Day 30 & Day 45 & Day 60 \\
\hline Group 1: Normal control & $18.53 \pm 2.06$ & $17.57 \pm 1.98$ & $19.90 \pm 1.45$ & $19.03 \pm 0.86$ \\
\hline Group 2: HLD control & $22.23 \pm 1.17$ & $63.83 \pm 2.17$ & $72.27 \pm 0.31^{\# \#}$ & $75.70 \pm 1.41$ \\
\hline Group 3: REGG 100 & $22.17 \pm 1.31$ & $66.53 \pm 1.74$ & $60.97 \pm 0.76^{* *, \# \#}$ & $43.30 \pm 1.79^{* *, \# \#}$ \\
\hline Group 4: REGG 200 & $21.77 \pm 1.04$ & $65.87 \pm 1.59$ & $46.50 \pm 0.85^{* *, \# \#}$ & $31.10 \pm 1.85^{* *}$ \\
\hline Group 5: Standard control & $23.13 \pm 1.67$ & $62.90 \pm 1.77$ & $40.30 \pm 0.95^{* *}$ & $30.27 \pm 1.61^{* *}$ \\
\hline
\end{tabular}

Data expressed as mean \pm SEM. $\mathrm{n}=6$ in each group. Significance at ${ }^{*} \mathrm{p}<0.05,{ }^{* *} \mathrm{p}<0.001$ as compared to HLD control. ${ }^{\#} \mathrm{p}<0.05$, ${ }^{\# \#} \mathrm{p}<0.001$ as compared to standard control. HLD: Hyperlipidemic diet, REGG 100 and REGG 200: Rind extract of Garcinia gummi-gutta at $100 \mathrm{mg} / \mathrm{kg}$ and $200 \mathrm{mg} / \mathrm{kg}$, Standard control: Atorvastatin $10 \mathrm{mg} / \mathrm{kg}$, LDL: Low-density lipoprotein cholesterol, SEM: Standard error of mean 
Table: 5: Effect of fruit rind extract of Garcinia gummi-gutta on VLDL cholesterol levels

\begin{tabular}{|c|c|c|c|c|}
\hline \multirow[t]{3}{*}{ Groups $(n=6)$} & \multicolumn{4}{|c|}{ VLDL levels (mg/dl) } \\
\hline & \multicolumn{2}{|c|}{ Induction of hyperlipidemia } & \multicolumn{2}{|c|}{ Drug administration } \\
\hline & Day 0 baseline & Day 30 & Day 45 & Day 60 \\
\hline Group 1: Normal control & $15.97 \pm 0.25$ & $15.93 \pm 0.26$ & $16.10 \pm 0.19$ & $16.47 \pm 0.22$ \\
\hline Group 2: HLD control & $16.77 \pm 0.17$ & $36.50 \pm 0.24$ & $39.57 \pm 0.59^{\# \#}$ & $40.80 \pm 0.64^{\# \#}$ \\
\hline Group 3: REGG 100 & $16.33 \pm 0.18$ & $36.30 \pm 0.22$ & $33.03 \pm 0.29^{* *, \# \#}$ & $29.70 \pm 0.35^{* *, \# \#}$ \\
\hline Group 4: REGG 200 & $16.23 \pm 0.22$ & $35.97 \pm 0.26$ & $28.67 \pm 0.29^{* *, \# \#}$ & $23.07 \pm 0.25^{* *, \#}$ \\
\hline Group 5: Standard control & $16.70 \pm 0.15$ & $36.10 \pm 0.15$ & $24.03 \pm 0.26^{* *}$ & $21.23 \pm 0.26^{* *}$ \\
\hline
\end{tabular}

Data expressed as mean \pm SEM. $n=6$ in each group. Significance at ${ }^{*} \mathrm{p}<0.05,{ }^{* *} \mathrm{p}<0.001$ as compared to HLD control, ${ }^{*} \mathrm{p}<0.05$, ${ }^{\# \#} \mathrm{p}<0.001$ as compared to standard control. HLD: Hyperlipidemic diet, REGG 100 and REGG 200: Rind extract of Garcinia gummi-gutta at $100 \mathrm{mg} / \mathrm{kg}$ and $200 \mathrm{mg} / \mathrm{kg}$, Standard control: Atorvastatin $10 \mathrm{mg} / \mathrm{kg}$, VLDL: Very low-density lipoprotein cholesterol, SEM: Standard error of mean

Table 6: Effect of fruit rind extract of Garcinia gummi-gutta on high-density lipoprotein cholesterol levels

\begin{tabular}{|c|c|c|c|c|}
\hline \multirow[t]{3}{*}{ Groups $(n=6)$} & \multicolumn{4}{|c|}{ HDL levels (mg/dl) } \\
\hline & \multicolumn{2}{|c|}{ Induction of hyperlipidemia } & \multicolumn{2}{|c|}{ Drug administration } \\
\hline & Day 0 baseline & Day 30 & Day 45 & Day 60 \\
\hline Group 1: Normal control & $28.17 \pm 0.87$ & $28.17 \pm 0.54$ & $28.50 \pm 0.76$ & $30.00 \pm 0.63$ \\
\hline Group 2: HLD control & $25.00 \pm 0.58$ & $27.00 \pm 1.26$ & $23.83 \pm 1.08^{\# \#}$ & $24.83 \pm 1.72$ \\
\hline Group 3: REGG 100 & $26.83 \pm 1.01$ & $29.00 \pm 0.86$ & $33.50 \pm 0.67^{* *, \# \#}$ & $36.17 \pm 0.98^{* *, \#}$ \\
\hline Group 4: REGG 200 & $26.17 \pm 1.17$ & $27.50 \pm 1.48$ & $37.83 \pm 1.25^{* *, \# \#}$ & $45.17 \pm 1.30^{* *}$ \\
\hline Group 5: Standard control & $26.00 \pm 0.86$ & $30.00 \pm 1.13$ & $41.67 \pm 0.88^{* *}$ & $42.17 \pm 1.22^{* *}$ \\
\hline
\end{tabular}

Data expressed as mean \pm SEM. $\mathrm{n}=6$ in each group. Significance at ${ }^{*} \mathrm{p}<0.05, * * \mathrm{p}<0.001$ as compared to HLD control, ${ }^{*} \mathrm{p}<0.05,{ }^{*} \mathrm{p}<0.001$ as compared to standard control. HLD: Hyperlipidemic diet, REGG 100 and REGG 200: Rind extract of Garcinia gummi-gutta at $100 \mathrm{mg} / \mathrm{kg}$ and $200 \mathrm{mg} / \mathrm{kg}$, Standard control: Atorvastatin $10 \mathrm{mg} / \mathrm{kg}$ HDL: High-density lipoprotein cholesterol, SEM: Standard error of mean

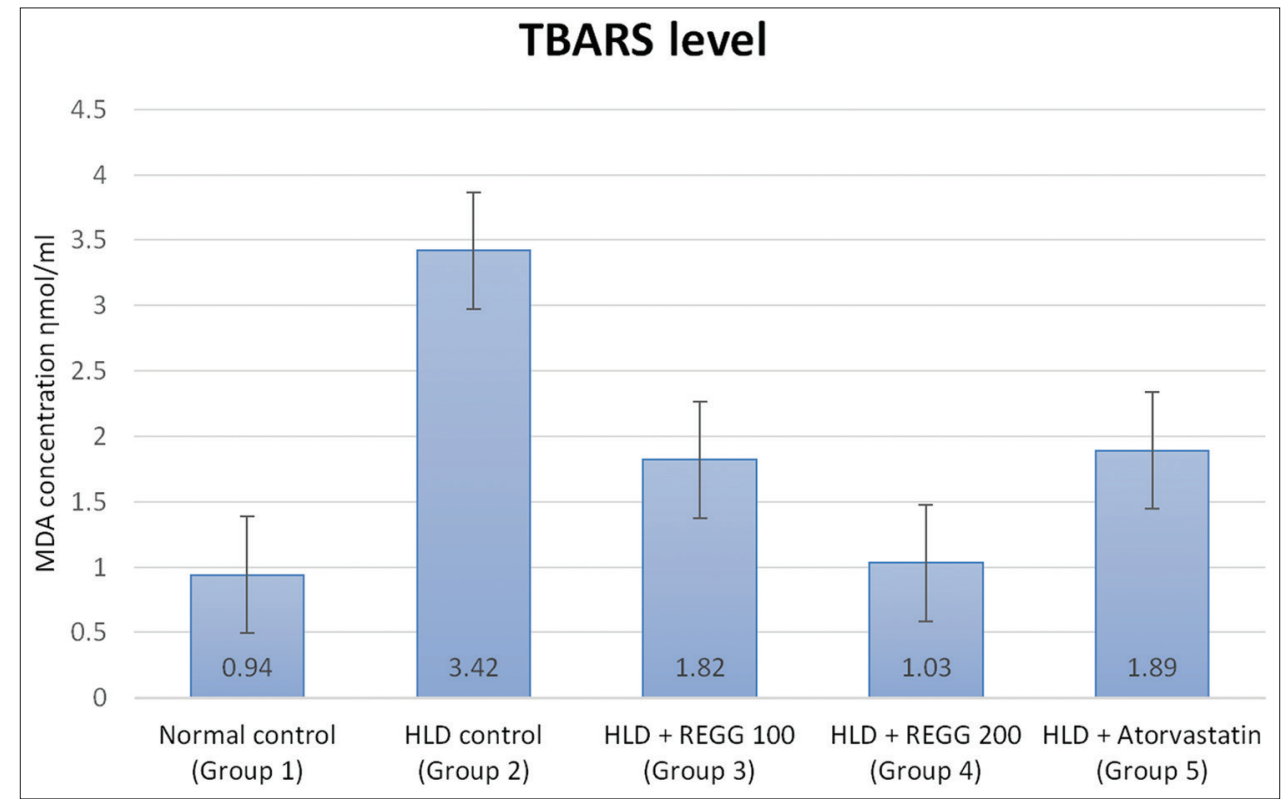

Fig. 1: Effect of fruit rinds of Garcinia gummi-gutta on thiobarbituric acid reactive substances levels. Values expressed in $\eta \mathrm{mol} / \mathrm{ml}$. $\mathrm{n}=6$ in each group. HLD - hyperlipidemic diet, REGG 100 and REGG 200 - rind extract of G. gummi-gutta at $100 \mathrm{mg} / \mathrm{kg} \mathrm{and} 200 \mathrm{mg} / \mathrm{kg}$

Effect of the rind extract of G. gummi-gutta on liver histopathology Histology of liver section of normal control exhibited normal hepatic cells each with well defined cytoplasm, prominent nucleus, and nucleolus with well defined central vein and sinusoids (Fig 2a). Rats which received HLD showed micro fatty deposits in the hepatocytes, congestion with mild distortion of the architecture, and early feathery degeneration (Fig. 2b). Hyperlipidemic rats which received REGG 100 showed mild cytoplasmic fatty deposits and periportal leucocyte infiltration (Fig. 2c), whereas hyperlipidemic rats which received REGG 200 showed mild periportal inflammation with infiltration of lymphocytes with well-preserved liver architecture (Fig. 2d). Histopathology of rats treated with HLD along with atorvastatin showed only mild sinusoidal congestion with overall preservation of normal hepatic architecture (Fig. 2e).

Effect of the rind extract of G. gummi-gutta on myocardial histopathology

Histopathological sections of the heart did not show significant changes. Fig. 3a shows normal histology of myocardial cells. Ovalelongated nucleus centrally surrounded with homogenous cytoplasm. 


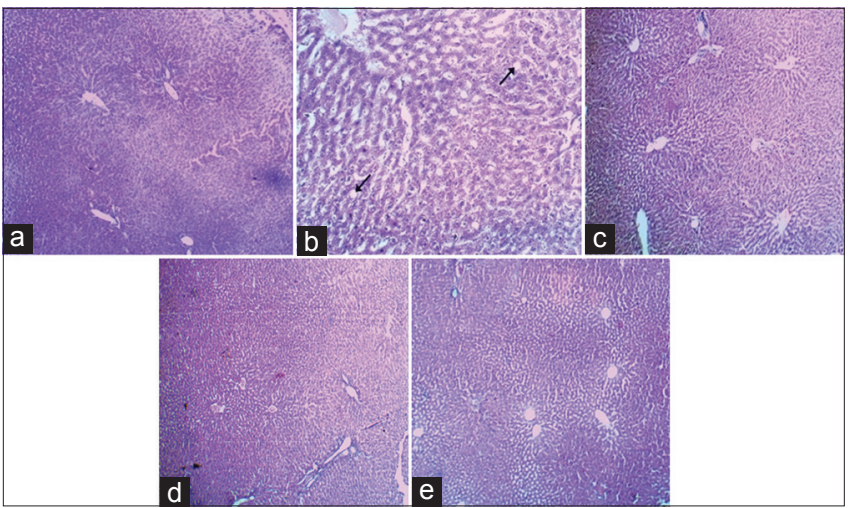

Fig. 2: Effect of the rind extract of Garcinia gummi-gutta on liver histopathology. Microphotograph of (a) normal liver, (b) hyperlipidemic diet, (c) REGG at $100 \mathrm{mg} / \mathrm{kg}$, (D) REGG at $200 \mathrm{mg} / \mathrm{kg}$, (e) standard control

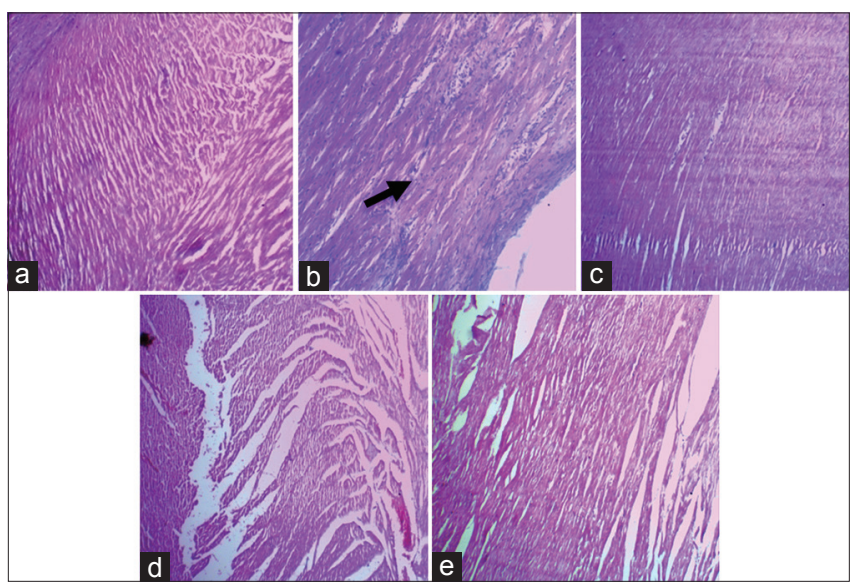

Fig. 3: Effect of the rind extract of Garcinia gummi-gutta on myocardial histopathology. Microphotograph of (a) normal myocardium, (b) hyperlipidemic diet, (c) REGG at $100 \mathrm{mg} / \mathrm{kg}$, (d) REGG at $200 \mathrm{mg} / \mathrm{kg}$, (e) standard control

Mild congestion with inflammatory infiltrates was seen with rats which received HLD (Fig. 3b). Hyperlipidemic rats which received the extracts at both doses and the standard controlgroup failed to produce significant changes preserving the overall myocardial integrity (Fig. 3c-e).

The extract at both doses not only halted the inflammatory process but was also able to reverse the condition. This provides conclusive evidence of the hepatoprotective and cardioprotective property of the extract.

\section{DISCUSSION}

In the present study, the hypolipidemic activity of fruit rind extract of G. gummi-gutta was investigated in diet-induced hyperlipidemic rat models.

The 8-week study was conducted in the Department of Pharmacology in collaboration with the Department of Pathology and Biochemistry in Mahatma Gandhi Medical College and Research Institute, Puducherry.

In our study, supplementation of fruit rind extract at two doses, that is, 100 and $200 \mathrm{mg} / \mathrm{kg}$, produced a dose-dependent reduction in the serum lipids along with significant reduction in lipid peroxidation.

In spite of daily HLD feeding, by the end of day 60 , there was a significant reduction of TC, TG, and VLDL in Group 3 with REGG administered at a lower dose $(100 \mathrm{mg} / \mathrm{kg})$. When given at a higher dose $(200 \mathrm{mg} / \mathrm{kg})$ Group 4 exhibited a marked reduction in TC, TG, and VLDL as compared to Group 2 and significant reduction as compared with the standard drug atorvastatin.

The results suggest that REGG at both doses reduced the de novo cholesterol biosynthesis and favored the redistribution of cholesterol among the lipoprotein molecules. This activity can be attributed to the presence of hydroxycitric acid (HCA) in the extracts which competitively inhibits ATP citrate lyase, the enzyme responsible for the extramitochondrial degradation of citrate to oxaloacetate and acetyl CoA, thus limiting the availability of two carbon units required for fatty acid and cholesterol biosynthesis $[6,14,15]$. In addition to the above mechanism, HCA initiates gluconeogenesis by converting excess blood lipids to glycogen. It also inhibits pancreatic alphaamylase and intestinal glucosidase diminishing intestinal carbohydrate absorption [16], and exhibits partial inhibition of HMG-CoA reductase, the key enzyme in cholesterologenesis [17].

In our study, treatment with REGG led to a significant elevation of plasma HDL-cholesterol (HDL-CH) in spite of daily HLD feed. A proportionate increase in HDL levels was observed at the end of 6 weeks with the extracts given at both doses. However, by the end of 8 weeks, the levels of HDL in Group 4 showed significant increase than the standard drug.

Of late, the crucial risk factor for CVD has been identified to be a low level of HDL-CH. Decreased levels of HDL-CH play a direct role in the atherogenesis, and therapeutic interventions promoting HDL-CH levels is widely encouraged. HDL by counteracting LDL oxidation prevents atherogenesis and, recent studies suggest that HDL promotes the reverse cholesterol transport pathway, by inducing an efflux of excess accumulated cellular cholesterol and prevents the generation of oxidized-LDL [18]. Furthermore, HDL not only inhibits the oxidation of LDL but also prevents the 12-lipoxygenase-mediated formation of lipid hydroperoxides [19]. Based on this, our results clearly suggest that fruit rind extract of G. gummi-gutta may probably exert their antiatherogenic role, partly by the inhibition of lipids oxidation (evident by reduction in the TBARS levels), and partly by the elevation of HDL-C.

For ages, LDL-CH has been identified as a potential target in CVD risk reduction therapy. Elevated LDL levels augmented with oxidative stress increase the risk of atherosclerosis and CVD [20]. In our study, significant reduction in LDL levels was observed with REGG administered at both the doses. However, values obtained were comparable to that of the standard control following administration of the extracts at higher doses. The biocompound HCA may probably be responsible for the reduction in LDL levels [21].

Most of the findings, in our study, were inconsistent with previous works conducted by Mahendran and Devi who in his study observed that the rind extract of G. cambogia at $1000 \mathrm{mg} / \mathrm{kg} /$ day for 8 days showed notable hypolipidemic activity on dexamethasone-induced hyperlipidemic rats. He also found that the extract was capable of normalizing increased levels of cholesterol and TG as well as free fatty acid following dexamethasone administration [22]. Similar to the above study, Ramos et al. observed that supplementation of the active principle HCA significantly increased HDL-C levels with a decrease in LDL levels [21]. Preuss et al. showed that HCA salt at $4.7 \mathrm{~g} /$ day in moderately obese subjects was capable of reducing food intake, TC, TG, and LDL levels while significantly increasing the levels of HDL and urinary excretion of fat metabolites [23]. Koshy et al. concluded that the flavonoid-rich rind extract exhibited hypolipidemic effect probably by lowering lipid turnover and increased metabolism [24].

The observation done by Leonhardt et al. was contradicting with our study findings, which showed supplementation of 3\% HCA did not result in decreased cholesterol levels [25]. Brandt et al. (2006) noted HCA (1.8\%) supplementation for 4 weeks resulted in an unexpected increase in liver lipid and postprandial cholesterolemia [26]. This may be due to an insufficient dose of HCA, which has failed to lower the serum lipids levels. 
Oxidative stress induced by HLD is associated with peroxidation of both cellular and circulating lipids which results in the formation of MDA. Quantifying this MDA will positively reflect the severity of an ongoing oxidative damage treatment with fruit rind extract of G. gummi-gutta significantly reduced the TBARS level in a dose-dependent manner. The increase in the MDA which is indicative of ongoing oxidative damage was due to oxidative stress induced by HLD [27]. In our study, a significant reduction in TBARS values was observed following treatment with the extract, wherein the maximum reduction was evident with a higher dose of the extract. Thus, it is evident that the rind extract possesses antioxidant properties at both doses, wherein the extract at higher dose exhibited strong antioxidant action compared to other groups. Our study findings were consistent with previous studies conducted by Kolodziejczyk et al. who in his study concluded that polyisoprenylated benzophenones such as garcinol and guttiferone $\mathrm{K}$ effectively reduced lipid peroxidation of LDL residues (reduced TBARS values), thereby indirectly counteracting oxidative stress in hyperlipidemia [28].

In our study, most of the histopathological findings were consistent with the obtained biochemical parameters. The fruit rind extract at both doses significantly reduced micro fatty deposits, periportal leukocytic infiltration, and disrupted architecture with higher doses showing evidence of hepatocellular recovery. REGG groups at both doses failed to show significant pathological changes in the myocardial cells. This may be due to the fact that hyperlipidemia primarily involves the vascular system and myocardial involvement in hyperlipidemia may be a late phenomenon. In our study, the fruit rind extracts at both the doses have effectively protected the myocardial cells from even the minor toxic insults of lipid peroxidation (signs of inflammation and fatty degeneration).

\section{CONCLUSION}

The present study demonstrated the hypolipidemic activity of G. gummi-gutta. The fruit rind extract at both doses was able to decrease the elevated serum lipids (TC, TG, LDL, and VLDL) and increase the HDL levels in a dose-dependent manner in spite of daily administration of HLD.

This reduction in lipid profile and TBARS may be probably due to the presence of HCA and other antioxidants in the extracts. Hence, further studies are warranted both in animals and humans before recommending for the clinical use in humans in the prevention and treatment of hyperlipidemia.

\section{ACKNOWLEDGMENTS}

We would like to acknowledge Dr. Dhananjay S. Kotasthane, Professor and Head and Dr. Vaishali D. Kotasthane, Assistant professor, Department of Pathology, and Mr. Kulanthaivel, Lecturer, Department of Biochemistry, MGMCRI, Pondicherry, India, for their valuable help and support.

\section{AUTHORS' CONTRIBUTIONS}

Dr. Barathane - conceptualized the study, compiled full literature search, and drafted the manuscript. Dr. Kartik. J Salwe - developed standards and edited the manuscript. Dr. Manimekalai - supervisor for the research work and provided guidance for the preparation of this article.

\section{DECLARATIONS}

Funding: Nil.

Ethical Approval: Approved by the Institutional Animal Ethics Committee.

\section{CONFLICTS OF INTEREST}

Nil.

\section{REFERENCES}

1. Abegunde DO, Mathers CD, Adam T, Ortegon M, Strong K. The burden and costs of chronic diseases in low-income and middle-income countries. Lancet 2007;370:1929-38.

2. Sample Registration System. Million Death Study: Preliminary Report on Causes of Death in India 2001-2003. New Delhi: Registrar General of India; 2007.

3. Indrayan A. Forecasting vascular disease cases and associated mortality in India. Reports of the National Commission on Macroeconomics and Health. India: Ministry of Health and Family Welfare; 2005.

4. Kondo A, Li J, Manabe M, Saito K, Kanno T, Maekawa M, et al. Relationship between high-density lipoprotein-cholesterol and malondialdehyde-modified low-density lipoprotein concentrations. J Atheroscler Thromb 2003;10:72-8.

5. Achuthan CR, Padikkala J. Hypolipidemic effect of Alpinia galanga (Rasna) and Kaempferia galanga (Kachoori). Ind J Clin Biochem 1997; $12: 55-8$

6. Stohs SJ, Preuss HG, Ohia S, Kaats G, Keen C, Williams L, et al. Safety and efficacy of hydroxycitric acid derived from Garcinia cambogia - A literature review. Herb Gram 2010;85:58-63.

7. Tharachand Selvaraj I, Avadhani M. Medicinal properties of Malabar tamarind [Garcinia cambogia (Gaertn.) Desr.]. Int J Pharm Sci Rev Res 2013;19:101-7.

8. Mahanta M, Mukherjee AK. Neutralisation of lethality, myotoxicity and toxic enzymes of Naja kaouthia venom by Mimosa pudica root extracts. J Ethnopharmacol 2001;75:55-60.

9. Blank B, Pfeiffer FR, Greenberg CM, Kerwin JF. Thyromimetics. II. The synthesis and hypocholesteremic activity of some beta-diethylaminoethyl esters of iodinated thyroalkanoic acids. J Med Chem 1963;6:560-3.

10. Diehl KH, Hull R, Morton D, Pfister R, Rabemampianina Y, Smith D, et al. A good practice guide to the administration of substances and removal of blood, including routes and volumes. J Appl Toxicol 2001;21:15-23.

11. Niehaus WG Jr., Samuelsson B. Formation of malonaldehyde from phospholipid arachidonate during microsomal lipid peroxidation. Eur J Biochem 1968;6:126-30.

12. Stocks J, Dormandy TL. The autoxidation of human red cell lipids induced by hydrogen peroxide. Br J Haematol 1971;20:95-111.

13. Carleton HM, Drury RA, Wallington EA. General staining procedures. In: Carleton's Histological Technique. $5^{\text {th }}$ ed. New York: Oxford University Press; 1980. p. 267.

14. Gogoi A, Gogoi N, Neog B. Dubious anti-obesity agent HCA from garcinia: A systematic review. Int J Pharm Pharm Sci 2015;7:1-8.

15. Sugden MC, Watts DI, Marshall CE, McCormack JG. Brown-adiposetissue lipogenesis in starvation: Effects of insulin and (-) hydroxycitrate. Biosci Rep 1982;2:289-97.

16. Altiner A, Ates A, EsenGursel F, Bilal T. Effect of the antiobesity agent Garcinia cambogia extract on serum lipoprotein (A), apolipoproteins $\mathrm{A} 1$ and $\mathrm{B}$, and total cholesterol levels in female rats fed atherogenic diet. J Anim Plant Sci 2012;22:872-7.

17. Offermanns S. Free fatty acid (FFA) and hydroxy carboxylic acid (HCA) receptors. Annu Rev Pharmacol Toxicol 2014;54:407-34.

18. Yokozawa T, Cho EJ, Sasaki S, Satoh A, Okamoto T, Sei Y, et al. The protective role of Chinese prescription Kangen-Karyu extract on diet-induced hypercholesterolemia in rats. Biol Pharm Bull 2006;29:760-5.

19. Nofer JR, Kehrel B, Fobker M, Levkau B, Assmann G, von Eckardstein A, et al. HDL and arteriosclerosis: Beyond reverse cholesterol transport. Atherosclerosis 2002;161:1-6.

20. Libby P, Ridker PM, Maseri A. Inflammation and atherosclerosis. Circulation 2002; 105:1135-43.

21. Ramos RR, Saenz JF, Aguilar MC. Control of obesity with Garcinia cambogia extract. Invest Med Int 1996;22:97-100.

22. Mahendran P, Devi CS. Effect of Garcinia cambogia extract on lipids and lipoprotein composition in dexamethasone administered rats. Indian J Physiol Pharmacol 2001;45:345-50.

23. Preuss HG, Bagchi D, Bagchi M, Rao CV, Dey DK, Satyanarayana S. Effects of a natural extract of (-)-hydroxycitric acid (HCA-SX) and a combination of HCA-SX plus niacin-bound chromium and Gymnema sylvestre extract on weight loss. Diabetes Obes Metab 2004;6:171-80.

24. Koshy AS, Anila L, Vijayalakshmi NR. Flavonoids from Garcinia cambogia lower lipid levels in hypercholesterolemic rats. Food Chem 2001;72:289-94.

25. Leonhardt M, Münch S, Westerterp-Plantenga M, Langhans W. Effects of hydroxycitrate, conjugated linoleic acid, and guar gum on food 
intake, body weight regain, and metabolism after body weight loss in male rats. Nutr Res 2004;24:659-69.

26. Brandt K, Langhans W, Geary N, Leonhardt M. Beneficial and deleterious effects of hydroxycitrate in rats fed a high-fructose diet. Nutrition 2006;22:905-12.

27. Sharma H, JoshiA, LadH, Bhatnagar D. Anti-oxidative, anti-inflammatory and anti-atherosclerotic effect of taurine on hypercholesterolemia induced atherosclerotic rats. Int J Pharm Pharm Sci 2018;10:145-50

28. Kolodziejczyk J, Masullo M, Olas B, Piacente S, Wachowicz B. Effects of garcinol and guttiferone $\mathrm{K}$ isolated from Garcinia cambogia on oxidative/nitrative modifications in blood platelets and plasma. Platelets 2009;20:487-92. 